\title{
Light-based science and technologies and human civilization: an optical course for general education
}

Xiaotong Li, Kaiwei Wang, Qing Yang, Ke Si

Xiaotong Li, Kaiwei Wang, Qing Yang, Ke Si, "Light-based science and technologies and human civilization: an optical course for general education," Proc. SPIE 10452, 14th Conference on Education and Training in Optics and Photonics: ETOP 2017, 104521K (16 August 2017); doi: 10.1117/12.2266843

EDEent: 14th Conference on Education and Training in Optics and Photonics, ETOP 2017, 2017, Hangzhou, China 


\title{
Light-based science and technologies and human civilization: an optical course for general education
}

\author{
Xiaotong Li, Kaiwei Wang ${ }^{*}$, Qing Yang, Ke Si \\ State key laboratory of modern optical instrumentation, College of optical science and engineering, \\ Zhejiang University, Hangzhou 310027, P. R. China
}

\begin{abstract}
Starting from 2015, a general education course named "Light-based science and technologies and human civilization" has been offered in Zhejiang University. We try to give a humanism view angle to observe optics and optical engineering, and combine them with the relationship between human and nature, the development of human society and human health. In this course we introduce different historical periods of light-based science and technologies, the great optical researchers, the typical research methods, advantages, academic discussions and the relationship with human civilization. The relevant cross-fields of learning and Nobel Prize winners are also included. This course provides the students with the typical examples about how academic revolution influences the world development, and also with humanism sight which exceeds the range of science and technologies.
\end{abstract}

Keywords: Optics education, general education, light-based science and technologies, human civilization, scientific literacy, humanism

\section{INTRODUCTION}

General education is different from professional education because the goal of it is to develop the students' personality, broaden and cross their knowledge. The students are educated as persons, not as engineers or employees. About general education we can track back to the ancient time, the liberal education in Academy created by Plato, and then contributed by Aristotle and many famous philosophers. In China we can track back to the Hundred Schools of Thought in Spring and Autumn and Warring States Period. In $19^{\text {th }}$ century the liberal education idea of Matthew Arnold was gradually recognized and implemented in well-known universities in the world. Now in more and more universities the students are advocated to take courses in humanities and arts. In Harvard University, the students are advocated to take general core courses and the intersection of arts and sciences in the education program.

In usual point of view the courses of literature, history, politics, moral and society are related to general education, while engineering and technologies have nothing to do with this goal. However, about eighty years ago the founder of the history of science George Sarton pointed out the importance of general education especially humanism education in disciplines of the fields of engineering and technology. On the other hand, some students from humanistic disciplines and social science know so little natural science and engineering that the arguments against scientific principles often appeared in videos and news.

Light is the source of life and the main source of information. The applications of light-based science and technologies have been providing many key solves to global problems, and becoming a primary cross-field of new science and engineering. Because of this, in 2013, the United Nations made a decision of the International Year of Light and Lightbased Technologies of 2015 at the $68^{\text {th }}$ session $^{1}$. The reasons of selecting the year 2015 included the vital applications of light science and technology for existing and future advances in many industries, services, energy and sustainable development, social health and well-being, and the year 2015 coincided with the anniversaries of a series of important milestones in the history of the science of light.

Just in 2015, we began to offer the course named "Light-based science and technologies and human civilization" as a general education course in Zhejiang University. We try to give a humanism view angle to observe optics and optical

*wangkaiwei@zju.edu.cn; phone (86)571-87951186; fax (86)571-87951186; opt.zju.edu.cn

14th Conference on Education and Training in Optics and Photonics: ETOP 2017, edited by Xu Liu,

Xi-Cheng Zhang, Proc. of SPIE Vol. 10452, 104521K · (c) 2017 ICO, IEEE, OSA, SPIE

CCC code: $0277-786 X / 17 / \$ 18 \cdot$ doi: $10.1117 / 12.2266843$

Proc. of SPIE Vol. $10452104521 \mathrm{~K}-1$ 
engineering, and combine them with the relationship between human and nature, the development of human society and human health.

Another reason of offering this course is that in China a high school student is expected by one's parents and school to get good enough score in the College Entrance Examination (the so-called gaokao), so as to be admitted to a favorite university. As a developing country, our university education resources are not rich enough, gaokao is so important to the students that they take more care of the courses with more scores in gaokao. Optics is still considered to be a branch of physics, and is not emphasized enough in high schools in comparison with mechanics and electromagnetism. Many people use the products of light-based technologies in daily life, but think that light and optics are far away from us. Because of above, one of our goals is to compensate for the lack of knowledge of the students in optics and optical technologies.

This course take the known earliest records about light as the beginning, the content includes different historical periods of light-based science and technologies, the great optical researchers, the typical research methods, advantages, academic discussions and the relationships with human civilization. The relevant cross-fields and Nobel Prize winners are also included.

Obviously, the public scientific literacy and the attitudes towards technology will affect the sustainable development. This course provides the students with the typical examples about how academic revolution influences the world development, and also with the humanism sight which exceeds the range of science and technologies.

Till now we have opened this course for 3 times. Our students come from disciplines of humanities and society, science and engineering.

\section{CONTENTS OF THE COURSE}

\subsection{Stars in history of optics}

Actually, the history of optics is as long as physics. Whether in the Orient or in the West there were many stars in ancient history. We take the ancient map in Turkey as a beginning, and give the students a mystery about prehistoric civilization.

We take some stars in Pre-Qin and ancient Greece periods, such as the "Light Eight" of Mozi (BC 468-BC376) in Mohist Classic including the law of linear propagation of light in the description of small hole imaging experiment, and the law of concave mirror imaging. But the area from the center to focus point of a concave mirror did not be described in Mohist Classic.

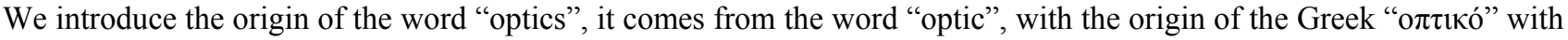
the meaning of something related to "vision". There were three theories of vision: the emission theory of Plato (BC427BC347), supported by Euclid (BC330-BC275) after some hundred years later, the incoming theory of Epicurus (BC341$\mathrm{BC} 270$ ), and the emission-incoming theory of Aristotle (BC384-BC322) and Ptolemy (90-168). From these the students can recognize that optics and the relevant technologies are around us all day long, all night long. Euclid's optics and his linking the vision to geometry, and Ptolemy's research on refraction are also the contents of the course.

Then we look back to the early 11th century to know the book of optics written by Ibn-al-Heitham (965-1039), and then the Centennial Translation campaign and the Renaissance, specially pay attention to the social development of that time.

Of course, Shen Kuo (1031-1095), Roger Bacon(1214-1294), Willebrord Snell (1580-1626), Pierre de Fermat(16011665), Isaac Newton (1643-1727), Johann Carl Friedrich Gauss (1777-1855), James Clerk Maxwell (1831-1879), Albert Einstein (1879-1955), Erwin Schrödinger (1887-1961), L. de Broglie (1892-1987), and many other great scientists are also stars in the history of optics. They are introduced in this course.

Not only great scientists, but also optical engineers are introduced to the students, just as Ernst Abbe (1840-1905) and Carl Zeiss (1816-1888). We give our respects to the stars for their contribution to today's development and our lives. We review the creation of the company Schott and Zeiss, and all kinds of precise optical instruments today, with thinking about the significance of industrialization of scientific and technological products, and the role in human history. For students from different specialties, entrepreneurial spirit is also a title to be thought. What is the most important to run a century business is also discussed in our class. 


\subsection{Academic contending and great inventions: the relationship with human civilization}

A classic academic contending that lasted from 17th century to 19th century was about the nature of light. The particle theory of light was supported by geometrical optics, while the wave theory of light was supported by interference and diffraction. Each of them had succeeded, but neither could explain all the light phenomena at that time. Till the end of 19th century, the wave-particle duality as the nature of light was finally recognized. This long period gives us a lesson that not everything has a definite option, and a clear boundary is not necessary for the nature of things. The seemingly contradictory parts are often combined together. The road to the truth is not straight. Contending is one of the ways to approach the truth.

We give some typical examples to demonstrate the relationship between optics and human civilization. Some examples are following:

(1) Galileo and his telescope

Galileo's observations on the sky directly supported the renewal of the view of universe, and his letter ${ }^{2}$ to the Grand Duchess Christina in 1615 as shown in figure 1 played an important role not only in optics or physics, but also in the history of political ideology. We provide the website to the students to read this letter from which we study his scientific spirit, and this is the true value of science.

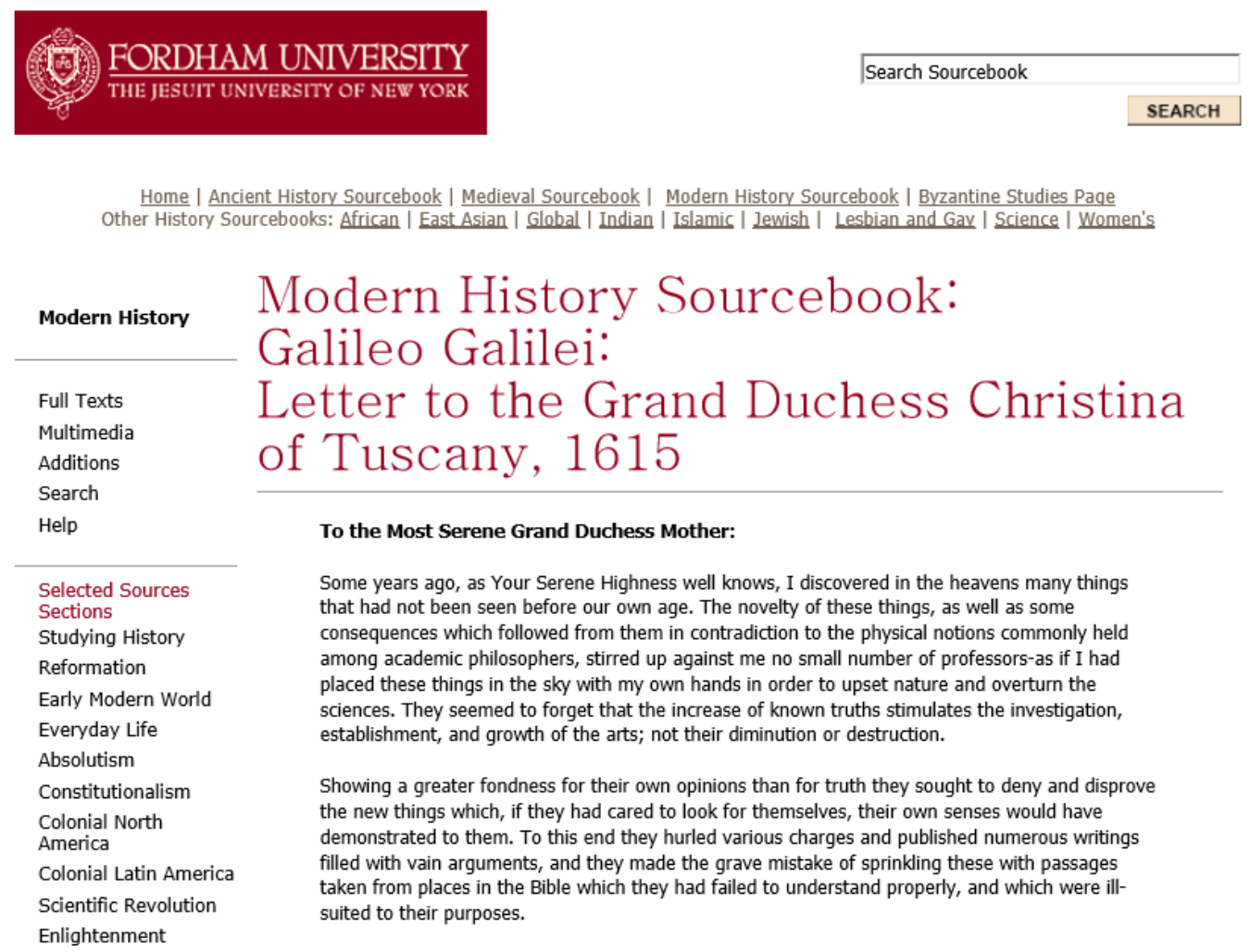

Figure 1. Galileo's letter to the Grand Duchess Christina in $1615^{2}$

(2) Photography and its being invented

As one of the greatest 100 inventions in human history, photography was invented by Louis Daguerre (1787-1851) in 1837 with the help of Nicéphore Niépce (1765-1833) and other researchers before. In 1839 France paid Daguerre for the right to present his invention to the world as the gift of France. Photography using lens and films became a very important method to remember history. The photos captured in the past or at other places told us what was the world like before we were born or at the places we were not be. In the two world wars, a lot of credible evidences were preserved by photography. Since CCD was invented in 1970, digital photography has created a new era. In our course the students study the knowledge of photography, how to take photos. They discuss the relations between photography and arts, 
photography and history, self-media and communication, image processing and application, some classical photos and they are true or false.

(3) Photo-communication and information-based society

This is a quite important content we cannot ignore. The information-based society is built upon the foundation of information dissemination. Optical technology changes the means of information communication, and makes the society more transparent. Education, trade, public management, their styles are quite different from before, just like they were changed by industrial revolution. This is one of the most typical examples that our lives and ideas are changed by lightbased technologies.

Spectral technology, material component detection and food safety, biological imaging, these topics tell the students about the relevance of optical technology and daily life, safety, remote sensing, resource prospecting, life sciences, and etc. Figure 2 is a screenshot about spatial resolution of biological imaging techniques. Figure 3 is a photo in our classroom where Dr. Kaiwei Wang was giving a lesion about the application of light-based technologies.

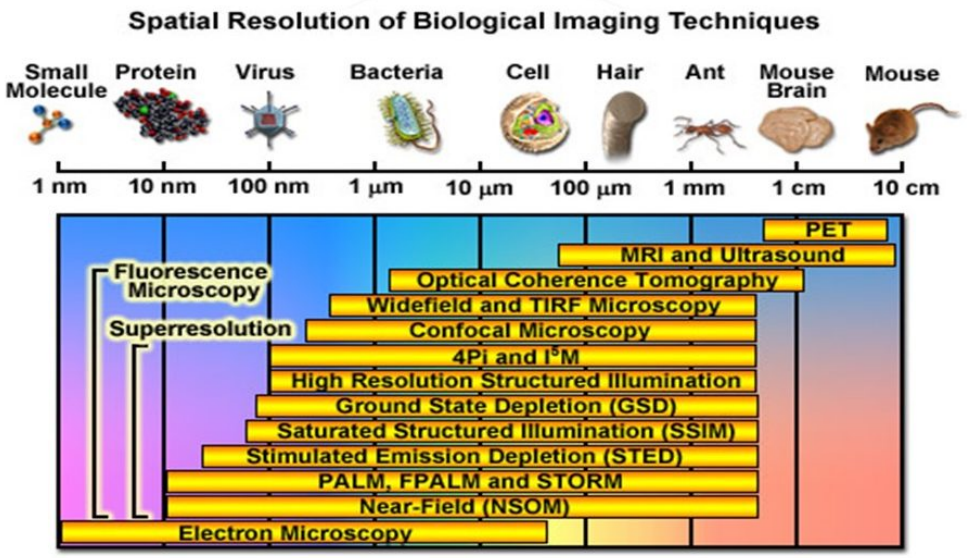

Figure 2. Spatial resolution of biological imaging techniques

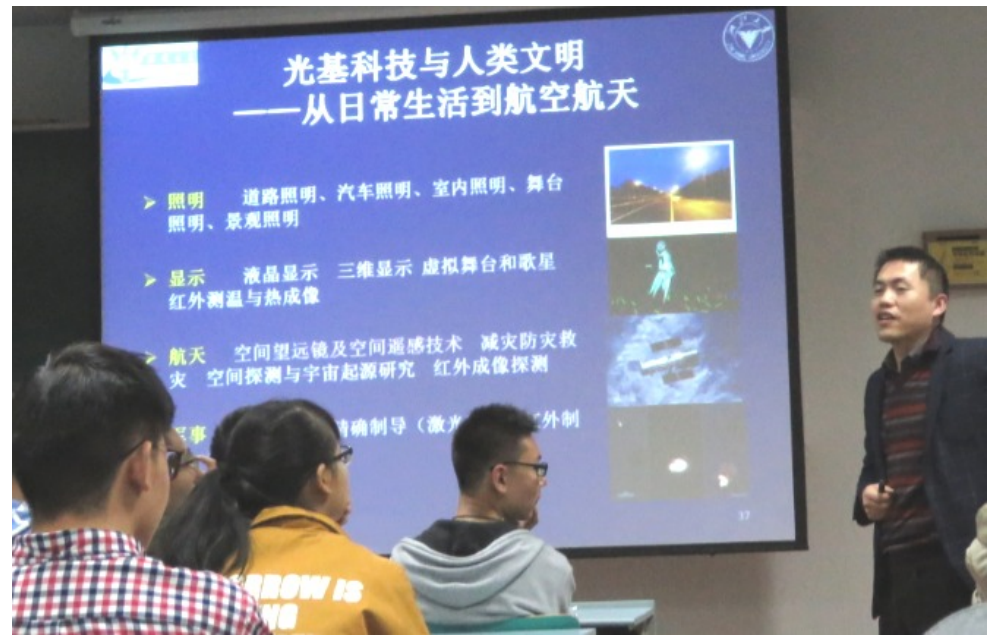

Figure 3. Dr. Kaiwei Wang was teaching: from daily life to aerospace

\subsection{Research melody}

In this course, we give some examples about research melody as following: 
(1) Induction and deduction

A typical example is the path from the law of linear propagation of light to Fermat's principle. This is a procedure of induction. As the same as above, Maxwell concluded his equations from 4 electric-magnetic equations. We draw a chart according to the time sequences shown in figure 4. Today, when we deduce the laws of geometrical optics, we make the Maxwell's equations as a beginning, then we deduce the wave equation, and then the ray equation or Lagrangian description of Fermat's principle as it was named is obtained. At last, from Fermat's principle the law of refraction (Snell's law), law of reflection, and the law of linear propagation of light can be obtained as shown in figure 5. This illustrate that looking forward and looking backward are the same important in discovering and invention.

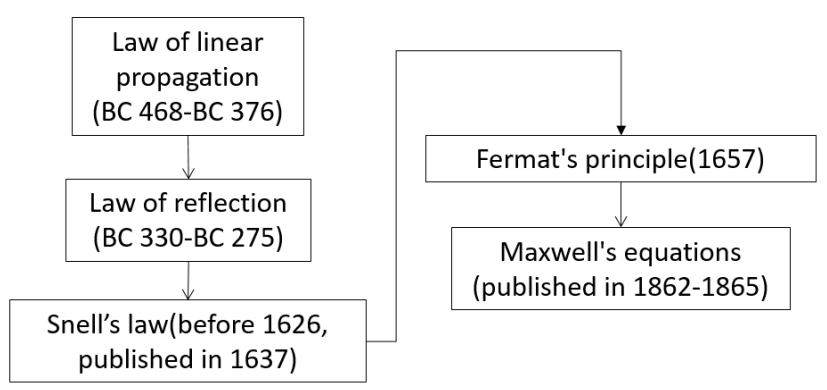

Figure 4. Time node of basic laws of geometrical optics

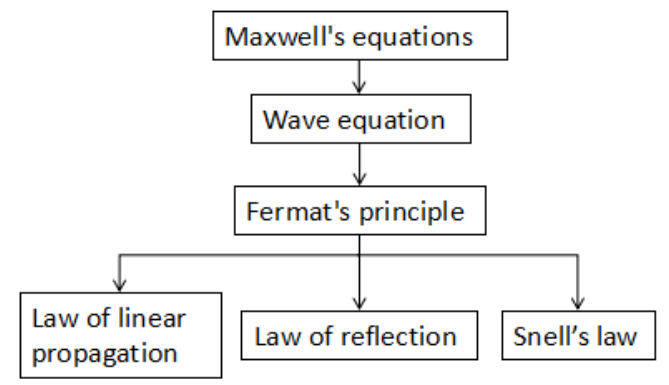

Figure 5. Deduction of the basic laws of geometrical optics

(2) Cross and integration of research fields

Although optics is seemed as a branch of physics, while it has become an interdisciplinary subject. In modern times the intersections of optics and other disciplines have derived novel subjects, such as biological imaging techniques, material science, ultrafast optics, nanooptics, optics and agriculture, optics and life science, optics and brain science, and etc.. These have become the new growth points of scientific development. To discover new phenomenon, new principles and new applications from the intersection point of different research fields is an important way of scientific research.

(3) Hypothesis, prediction and experiments

From hypothesis to prediction and then to confirmation, it is a common path for many scientific discoveries. Einstein predicted the stimulated radiation in $1917^{3}$, till 1960 Townes and other researchers invented the laser. Now laser has been applied in a number of fields including communication, fabrication, measure, information storage, and as a driver of controlled nuclear fusion, and etc. Maxwell established his equations, and predicted that light is electromagnetic wave, this prediction was verified in 1888 by experiments of Heinrich Rudolf Hertz (1857-1894). These events illustrate that assumptions and predictions based on reasonability are also important research methods.

\subsection{Nobel Prize winners and their contribution to human civilization}

One lesson about the Nobel Prize winners and their contribution to the world is arranged in the teaching plan.

In 2014, the Nobel Prize in Physics was awarded jointly to three blue LED inventors, "for the invention of efficient blue light-emitting diodes which has enabled bright and energy-saving white light sources." ${ }^{4} \mathrm{We}$ review the development of light source, take the invention of blue LED as an example of field-cross innovation of optics and material science, and to explore its meaning in sustainable development and saving energy from the award ceremony speech, in which the 
important events were reviewed including that our ancestor mastered the fire about 300,000 years ago, Thomas Edison (1847-1931) invented electric bulb in the late 19th century and LED was invented and improved.

In 2009, the father of optical fiber Kuen Kao and the CCD inventors Boyle and Smith awarded the prize. As said in the award ceremony speech", "we can phone someone on the other side of the globe and have a conversation while enjoying the same sound quality as if we were talking to someone in the same room. Likewise, we take it for granted that we can view photos and video reports of events on other continents at the same instant as they unfold. Our computers are linked up to the world-wide Internet, which has become an almost indispensable element of modern society. It provides efficient communication channels between people and quick access to the information we need at the moment."

Obviously, one hour of lesson is not enough to know every Nobel Prize winner. We can only pick up a few leaves in the forest of Nobel Prize winners.

\subsection{Advantages and disadvantages of light-based technologies}

In our course the disadvantages of light-based technologies are the same important as their advantages. This is because when a novel technology is invented, it brings us not only the resolves to certain problems, but also brings us new problems. For example:

Considering the city lighting and lighting pollution, can we today live again under the brilliant stars of our childhood?

Industrialization caused today's rich-poor gap. Will informatization cause the rich-poor gap in future? Is the Matthew effect also exist in the process of informatization? Is it good or bad that the robots enter the assembly line and lead to the unemployment of simple labor? How to remove the digital gap? What can we do for this?

Does internet addiction affect people's social interaction? Are human-machine relations becoming closer while the interpersonal relations becoming impersonal?

Are science and technology always civilized? Are there forbidden areas in science research? If so, what areas?

What will the earth be like in future?

There are no standard answers of these questions. These are the problems that should be considered by everyone.

\section{ORGANIZE THE LEARNING ACTIVITIES}

Discussion is an important study activity in which the students present their opinions in study groups. There are 50 80 students in one teaching class. They are divided into 7 9 study groups. We have one teaching unit including 3 class hours of lecture and 2 class hours of discussion every 2 weeks. In each unit we put forward 4 or 5 questions for discussion, covering basic knowledge, forecasts and imagination, the research methods of scientists, the relationship between light-based technology and civilization.

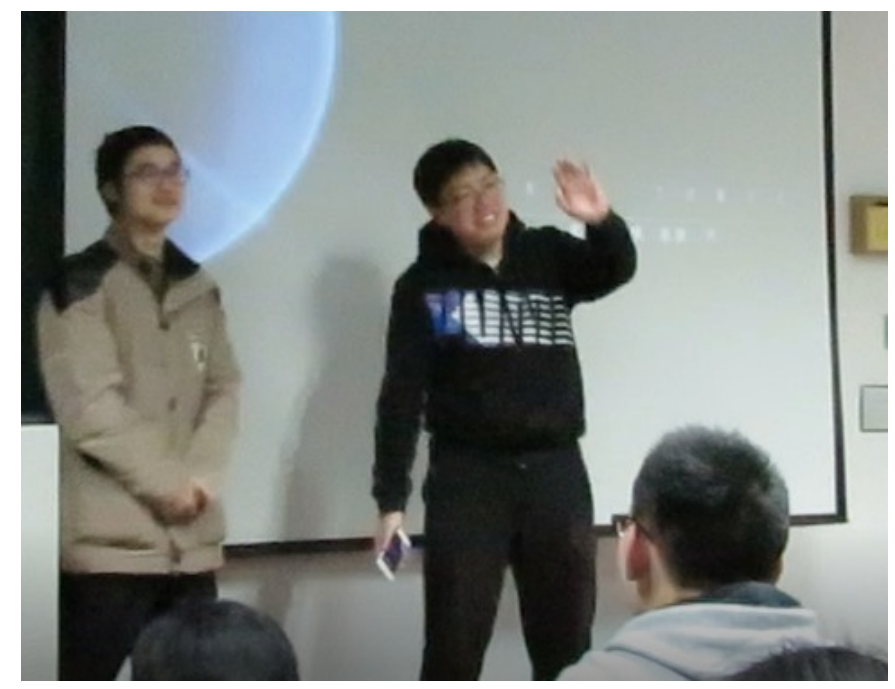

Figure 6. A drama performed by the students: a conversation between L. Daguerre and W. S. Boyle across time and space 
The students in each group must write the discussion reports every 2 weeks by collecting information and communication. According to the progress of the course, they will also make presentations of their discussion reports. When learning some units, they will be divided into two opposite teams to debate. For a particular light-based technique, such as photography, sometimes each group writes a little drama in which a conversation between Louis Daguerre and Willard S. Boyle across time and space is performed, as shown in figure 6. All of the activities are used to evaluate the students.

\section{CONCLUSION}

We have offered the course for two years. We are trying to combine engineering technology with social development and human civilization to give such a course for general education, and hoping that our students can learn their specialties with humanistic spirit. We also try to realize a universal education in modern light-based science and technology, and broaden the scope of general education. In this process we are supported by the students, they give us very good advice. They take part in the discussions, lectures, debates, performances and other learning activities with enthusiasm. In the future we will continue to improve the content of this course, enrich learning activities, and attract more students from different specialties, so as to help them to make progress in learning light-based technologies and develop the humanistic spirit.

\section{ACKNOWLEDGEMENT}

All the work in this paper is supported by the Office of Teaching Affairs of Zhejiang University, and the Education Administration Office of College of Optical Science and Engineering, Zhejiang University.

\section{REFERENCES}

[1] United Nations General Assemply, "Globalization and interdependence: science and technology for development," Sixty-eighth session, 9 December 2013, $<$ http://www.un.org/en/ga/search/view_doc.asp?symbol=A/68/440/Add.2\&referer=http://www.un.org/en/events /observances/years.shtml\&Lang $=\mathrm{E}>(3 \overline{0}$ April 2017)

[2] Paul Halsall, "Modern History Sourcebook: Galileo Galilei: Letter to the Grand Duchess Christina of Tuscany, 1615," Fordham University, 1 August 1997, <http://sourcebooks.fordham.edu/halsall/mod/galileo-tuscany.asp> (30 April 2017)

[3] Grifantini Kristina, "Year of the laser," Technology Review, 113(2), 26-31(2010)

[4] The official web site of the Nobel Prize, "The Nobel Prize in Physics 2014 - Presentation Speech," Nobel Media AB, 10 December 2014, <http://www.nobelprize.org/nobel_prizes/physics/laureates/2014/presentationspeech.html $>$ (30 April 2017)

[5] The official web site of the Nobel Prize, "The Nobel Prize in Physics 2009 - Presentation Speech," Nobel Media AB , 10 December 2009, <http://www.nobelprize.org/nobel_prizes/physics/laureates/2009/presentationspeech.html $>$ (30 April 2017) 